\title{
Vers la recuperació dels corredors fluvials metropolitans. El cas de la conca del Besòs a la regió metropolitana de Barcelona
}

\section{Marta Benages-Albert Pere Vall-Casas}

Universitat Internacional de Catalunya. Escola Tècnica Superior d'Arquitectura Laboratori de l'Àrea d'Urbanisme martabenages@uic.es perevall@uic.es

\section{Resum}

L'article analitza les estratègies desenvolupades durant els darrers trenta anys a favor de la recuperació dels rius i les rieres de la conca del Besòs. S'hi constata el reconeixement progressiu del valor social del paisatge fluvial i un cert trànsit des de la pedagogia tutelada per l'Administració fins a l'acció participada de la ciutadania. Per tal de reforçar el compromís ciutadà en el moment actual del procés regenerador, esdevé estratègica l'aposta per la diagnosi geoetnogràfica que permet accedir al coneixement vivencial dels espais fluvials. La comprensió dels mecanismes d'utilització i apropiació ciutadana és el primer pas ineludible per activar la implicació de les comunitats locals, com també, en darrera instància, per impulsar veritables projectes territorials participats a l'entorn dels corredors fluvials metropolitans.

Paraules clau: corredors fluvials metropolitans; projecte territorial; diagnosi geoetnogràfica; participació ciutadana; paisatge fluvial.

Resumen. Hacia la recuperación de los corredores fluviales metropolitanos. El caso de la cuenca del Besós en la región metropolitana de Barcelona

El artículo analiza las estrategias desarrolladas durante los últimos treinta años a favor de la recuperación de los ríos y las rieras de la cuenca del Besós. Se constata el progresivo reconocimiento del valor social del paisaje fluvial, así como un cierto tránsito desde la pedagogía tutelada por la Administración hasta la acción participada de la ciudadanía. A fin de reforzar 
el compromiso ciudadano en el momento actual del proceso regenerador, resulta estratégica la apuesta por la diagnosis geoetnográfica que permite acceder al conocimiento vivencial de los espacios fluviales. La comprensión de los mecanismos de utilización y apropiación ciudadana se perfila como el primer paso ineludible para activar la implicación de las comunidades locales, así como, en última instancia, para impulsar auténticos proyectos territoriales participados en torno a los corredores fluviales metropolitanos.

Palabras clave: corredores fluviales metropolitanos; proyecto territorial; diagnosis geoetnográfica; participación ciudadana; paisaje fluvial.

Résumée. Vers la reconquête des corridors fluviaux métropolitains. Le cas du bassin du Besòs dans la région métropolitaine de Barcelone

Le document examine les stratégies développées au cours des 30 dernières années en faveur de la restauration des rivières et des ruisseaux dans le bassin du Besòs. Il témoigne d'une reconnaissance progressive de la valeur sociale du paysage fluvial, et du passage d'une pédagogie dirigée par l'administration vers l'action participante des citoyens. Afin de renforcer l'engagement citoyen dans le processus de restauration en cours, l'analyse géoethnographique devient une approche stratégique pour la connaissance des espaces fluviaux en tant qu'espaces vécus. Comprendre les pratiques spatiales et les formes d'appropriation citoyenne devient une première étape essentielle pour développer l'engagement des communautés locales et, en fin de compte, stimuler de véritables projets territoriaux participatifs dans les corridors fluviaux métropolitains.

Mots clé: corridors fluviaux métropolitains; projet territorial; analyse géo-ethnographique; participation citoyenne; paysage fluvial.

Abstract. Towards the recovery of the metropolitan river corridors. The case of the Besòs basin in the Barcelona metropolitan region

The paper examines the strategies developed over the past 30 years in favor of the recovery of rivers and streams in the Besòs basin. The analysis reflects a shift from administration lead pedagogy to community based actions, as well as the progressive recognition of the riverscape's social value. Therefore, in current regeneration processes, a geo-ethnographic diagnosis is required and seems strategic in order to understand river areas as lived spaces and propel citizen engagement. The knowledge of the existing mechanisms of public use and citizen appropriation will activate local community involvement and, ultimately, foster true community-based regional projects around metropolitan river corridors.

Keywords: metropolitan river corridors; regional project; geo-ethnographic diagnosis; community involvement; riparian landscape.

\section{Sumario}

1. Els corredors fluvials.

D'eixos de creixement a espais públics metropolitans

2. La integració progressiva del component social en la gestió dels cursos fluvials de la conca del Besòs
3. La diagnosi geoetnogràfica en la regeneració participada dels cursos fluvials metropolitans

4. Consideracions finals

Referències bibliogràfiques 


\section{Els corredors fluvials. D'eixos de creixement a espais públics metropolitans}

Els corredors fluvials tenen un paper essencial en la vertebració de les regions metropolitanes. Aquests espais geogràfics allotgen sovint importants vies de comunicació i extensos continus urbanitzats amb mixtures complexes d'infraestructures, teixits urbans i espais oberts. La gestió que se'n faci requerirà una visió territorial renovada, capaç d'assumir el funcionament i la morfologia de la ciutat metropolitana contemporània, més enllà dels límits administratius i el marc normatiu vigent (Font, 2004). Igualment, la complexitat del paisatge de ribera necessita enfocaments que combinin, des d'una perspectiva global, anàlisis simultànies a escales múltiples, encaminades a integrar l'estructura pròpia de cada nivell en un conjunt congruent (Panareda, 2009).

El valor estratègic dels corredors fluvials és especialment significatiu en el cas de la regió metropolitana de Barcelona, on, a partir de la dècada de 1950, les valls del Llobregat i del Besòs es transformen en eixos de desenvolupament territorial (Comisión Provincial de Urbanismo de Barcelona, 1963; Vendrell i Presmanes, 1993). L'aprofitament agrícola tradicional dels recursos hídrics es va veient substituït progressivament per l'abastament a la població i a les activitats industrials creixents; mentre l'activitat agrària, encara rellevant en alguns àmbits fluvials, recula indefectiblement. El cas del port i de l'aeroport, al delta del Llobregat, o el centre d'intercanvi de mercaderies CIM Vallès, a la riera de Caldes, il.lustren aquesta dinàmica. Es pot afirmar que els cursos fluvials metropolitans han esdevingut actualment eixos de comunicació viària i ferroviària de la ciutat central amb les corones metropolitanes successives; eixos d'urbanització conformats per agregació de teixits residencials, industrials i nodes de servei metropolità (Font et al., 1999; Vecslir, 2007), a més de canals de desguàs i subministrament d'energia (García i Godé, 2006).

La sobreexplotació dels recursos hídrics i la degradació dels ecosistemes, ocasionades per la pressió antròpica (Prat et al., 1982-1983; Prat i Rieradevall, 1992), activen, a partir de la dècada de 1980, l'adquisició progressiva en cercles tècnics i polítics d'una nova consciència ambiental. Prèviament, però, a les acaballes del franquisme, la comunitat científica ja alertava sobre la contaminació dels rius i dels aqüífers a causa d'una gestió deficient dels recursos hídrics (Díaz i Queralt, 1970; Planas et al., 1976; Queralt, 1974; Cantó et al., 1975). A finals de la dècada de 1970, l'horitzó de la integració europea i la consegüent obligació d'abordar seriosament el sanejament de les aigües residuals va propiciar l'encàrrec de la diagnosi de l'estat ecològic dels rius catalans al Departament d'Ecologia de la Universitat de Barcelona, concretament, a l'equip liderat, primer, per Ramon Margalef $\mathrm{i}$, uns quants anys després, per Narcís Prat (Margalef i Prat, 1979; Prat, 1979). D’altra banda, paral.lelament a aquest procés de conscienciació ambiental induït "des de dalt», la pressió social «des de baix», desencadenada per situacions alarmants com ara els brots epidèmics i les inundacions, va esdevenir decisiva per legitimar les decisions polítiques encaminades a millorar la gestió de l'aigua. A poc a poc, el riu deixa 
de ser percebut com un simple canal d'aigua que circula per un espai residual i s'aposta per fer-ne una recuperació ambiental complexa i integrada (Simon, 1994; Vendrell, 1994; AADD, 1994). En aquest context, la revaloració progressiva del paisatge de ribera permet superar l'oblit al qual havia quedat relegat en dècades anteriors (Panareda, 2009), i la figura del parc fluvial irromp amb força com a espai de lleure $\mathrm{i}$ instrument estratègic de regeneració metropolitana (Torra et al., 2008). A les portes del segle XXI, els corredors fluvials formen part del sistema d'espais públics metropolitans i, més enllà de l'estricta funció ecològica, assumeixen també un rol social i econòmic important.

Pel que fa al rol social, els rius i les rieres són indrets intensament reivindicats com a espais de lleure i retrobament amb la natura (Batlle, 2011; Vallerani, 2012). Els cursos fluvials, juntament amb els boscos i els espais agraris immediats, conformen el paisatge quotidià de molts ciutadans, fomenten la cohesió i la identitat local i compensen la manca d'espais públics convencionals dels teixits residencials propers (Benages, 2011). Per això, l'aposta a favor d'un ús social responsable i d'una relectura cívica del sistema hídric (Vall, 2010; Vall et al., 2011), seguint l'exemple pioner del Boston Park System de la segona meitat del segle XIX (Zaitzevsky, 1982), esdevé essencial per a la integració física i social de la regió metropolitana (Torra et al., 2008; Generalitat de Catalunya, 2010b). Actualment, aquest model és revisat tenint en compte demandes noves (Platt, 2006; Forman, 2004), entre les quals la salut pública adquireix un relleu especial, atesa la incidència directa que la millora ambiental dels rius i l'increment de la seva accessibilitat pot comportar en la promoció d'estils de vida saludables i, consegüentment, en la salut dels ciutadans i la reducció de la despesa mèdica (Nilsson i Nielsen, 2006; Nogué et al., 2008; Rydin et al., 2012).

Pel que fa al rol econòmic, els rius i les rieres tenen també un paper important en la configuració dels corredors productius, característics de l'arc metropolità de Barcelona, que aprofiten la topografia amable de les planes fluvials i la connexió privilegiada amb la ciutat central. Els corredors de Granollers i Sabadell, organitzats a l'entorn del riu Congost i del riu Ripoll, exemplifiquen la presència recurrent d'aquests espais productius distingits pel seu dinamisme (Trullén, 2003). En aquest context, la millora de la qualitat de l'espai fluvial contribueix a facilitar la consolidació progressiva d'activitats productives de més valor afegit (Morris, 2003) i, en definitiva, incrementa la competitivitat de la regió metropolitana en el marc d'una nova economia. El corredor de la riera de Caldes exemplifica aquesta tendència amb la implantació d'instal.lacions dels sectors informàtic i farmacèutic, $\mathrm{i}$ especialment d'unitats no directament productives dedicades a usos direccionals, atretes per un sòl industrial de qualitat equipat amb grans parcs de ribera (Generalitat de Catalunya, 1987, 1988). En aquesta línia, estudis recents suggereixen que, a la regió metropolitana de Barcelona, factors com ara la qualitat ambiental de l'espai, juntament amb l'accessibilitat als serveis d'alt valor afegit i el prestigi socioempresarial de les localitzacions, esdevenen determinants per a l'emplaçament d'activitats econòmiques vinculades al coneixement i la innovació (Pérez i Marmolejo, 2008). 
L'interès econòmic i social dels corredors fluvials de la regió metropolitana de Barcelona, afegit a la reconeguda importància viària i ambiental, aconsellen abordar-ne l'ordenació des d'una visió urbanística integrada. Aquest enfocament ha estat àmpliament assumit en cercles tècnics (Llop, 2008), i el propi Pla Territorial Metropolità vigent (Generalitat de Catalunya, 2010b) ha previst el desenvolupament de plans directors urbanístics adreçats a conciliar els objectius ecològics, econòmics i socials plantejats a l'entorn d'alguns eixos fluvials, com ara la vall del Tenes i la riera de Caldes. Aquests plans han estat concebuts com a instruments de concertació tècnica, política i social (Nel.lo, 2006). Per aquest motiu, la gestió adequada de la participació ciutadana adquireix una importància especial. En aquest sentit, és generalment acceptat que una base social sòlida reforça el contingut tècnic del pla i en permet la correcta implementació (Kaplan et al., 1998; Nogué, 2010). Amb aquest propòsit, el projecte territorial participat es converteix segurament en la via més ferma per assolir el consens i els compromisos necessaris per regenerar els corredors fluvials metropolitans.

D'altra banda, el projecte territorial participat també permet establir les bases per construir identitats territorials vigoroses. Pel que fa a aquesta qüestió, és important remarcar que l'accés a l'espai natural és un factor de qualitat de vida àmpliament reconegut. Els ciutadans valoren la seva vinculació als entorns naturals $i$ adquireixen progressivament una consciència ambiental associada als sentiments de pertinença i autoestima (Kaplan et al., 1998; Barba, 1994; Luginbühl, 2008; Morris, 2003). Per aquest motiu, la construcció d'identitats territorials consistents a l'entorn de rius i rieres requereix una recuperació del paisatge fluvial compromesa amb la millora de la qualitat de vida dels habitants riberencs i el foment de les especificitats físiques i socials a través de processos de participació ciutadana.

Cal recordar, però, que els procediments participatius són complexos i, malauradament, encara no estan prou assentats en la nostra pràctica urbanística habitual, que tendeix a relegar a un segon terme la dimensió social del territori i $\mathrm{a}$ atorgar més importància a aspectes morfològics i funcionals. D'altra banda, a la voluntat d'impulsar la participació ciutadana, li manca sovint el suport tècnic necessari (Fernández, 2010; Gutiérrez, 2009; Brugué, 2009), i la implicació de la població en les iniciatives de restauració dels espais fluvials resta encara minoritària. Però, davant d'aquestes dificultats, la societat en xarxa i les tecnologies de la informació poden facilitar i amplificar els processos participatius (Cámara, 2012), com també consolidar els avenços significatius que ha experimentat Catalunya cap al desenvolupament d'una nova cultura del territori basada en la "construcció social del paisatge» (Cortina, 2010; Nogué, 2010).

En aquest context, es considera necessari perseverar en els esforços de recerca adreçats a donar suport a la regeneració dels corredors fluvials metropolitans de Barcelona mitjançant projectes territorials participats. El present article se situa en aquesta línia i té per objectiu raonar l'interès de la diagnosi geoetnogràfica en l'estadi actual del procés de revaloració en curs de la conca del Besòs. Aquest treball, malgrat que es desenvolupi a l'entorn d'un cas particular, pretén contribuir a realitzar una reflexió de caràcter més general sobre la conveniència d'incorporar la diagnosi geoetnogràfica en la pràctica ordinària de la gestió i 
l'ordenació dels cursos fluvials de la regió metropolitana de Barcelona, per tal de superar les limitacions metodològiques del marc actual. Per aquest propòsit, juntament amb la introducció present, on s'argumenta el valor estratègic dels corredors fluvials i la idoneïtat del projecte territorial participat per abordar-ne la recuperació, l'article es compon de tres apartats. Al primer, s'hi revisen les estratègies desenvolupades des de cercles tècnics i polítics durant els darrers trenta anys pel que respecta a la incorporació progressiva del component social en la revaloració de la conca del Besòs. S'hi pren consciència de les limitacions de l'utillatge tècnic emprat $\mathrm{i}$, alhora, s'hi constata la necessitat d'incorporar-hi eines noves per tal d'endegar un projecte territorial realment participat. Al segon apartat, s'hi introdueixen les coordenades conceptuals bàsiques de la diagnosi geoetnogràfica mitjançant referències a la literatura especialitzada i a casos internacionals emblemàtics. Finalment, en unes breus consideracions finals, s'hi valora la integració de l'instrument proposat en el marc del planejament vigent.

\section{La integració progressiva del component social en la gestió dels cursos fluvials de la conca del Besòs}

La conca del Besòs, emmarcada entre les serralades Prelitoral i Litoral, discorre majoritàriament per la depressió del Vallès i està composta per sis cursos fluvials principals: el Mogent, el Congost, el Tenes, la riera de Caldes, el Ripoll i el Besòs. Més de dos milions d'habitants viuen en els sistemes urbans articulats a l'entorn d'aquests cursos fluvials i posen en evidència la dimensió social d'aquest sistema hídric, abocat a esdevenir un sistema d'espais públics de rang metropolità (figura 1). L'anàlisi de la conca del Besòs va ser abordada minuciosament, a finals de la dècada de 1940, pel geògraf Josep M. Puchades a la seva obra El río Besós: Estudio monográfico de hidrología fluvial (Puchades, 1948), on es reclamava per primera vegada una visió sistèmica del medi fluvial per afrontar els impactes negatius derivats de la sobreexplotació a la qual era sotmès. En sintonia amb aquesta aportació seminal, la revaloració ambiental i social de la conca del Besòs ha marcat les agendes de l'Administració i de nombroses entitats civils durant les tres últimes dècades (Gordi, 2008; Torra et al., 2008). Al llarg d'aquest temps, l'enfocament de la regeneració fluvial ha evolucionat, a grans trets, des d'una visió inicial, sectorial i paramètrica, bàsicament orientada a controlar la quantitat i la qualitat de l'aigua, fins a la visió actual, més unitària i complexa, que reconeix la integritat del paisatge fluvial i la necessària implicació del ciutadà per mantenir-la. Les directives europees referents a l'aigua i al paisatge (Consell d'Europa, 2000a i 2000b) han tingut un paper cabdal en aquesta evolució que tot seguit s'analitza.

\subsection{La millora urgent de la qualitat de l'aigua i la visió sectorial del riu}

A principis de la dècada de 1980, l'alarmant degradació dels recursos hídrics, la demanda creixent d'aigua i la sobrepressió urbana dels corredors fluvials metropolitans, heretades dels darrers anys del franquisme, reclamen a les admi- 


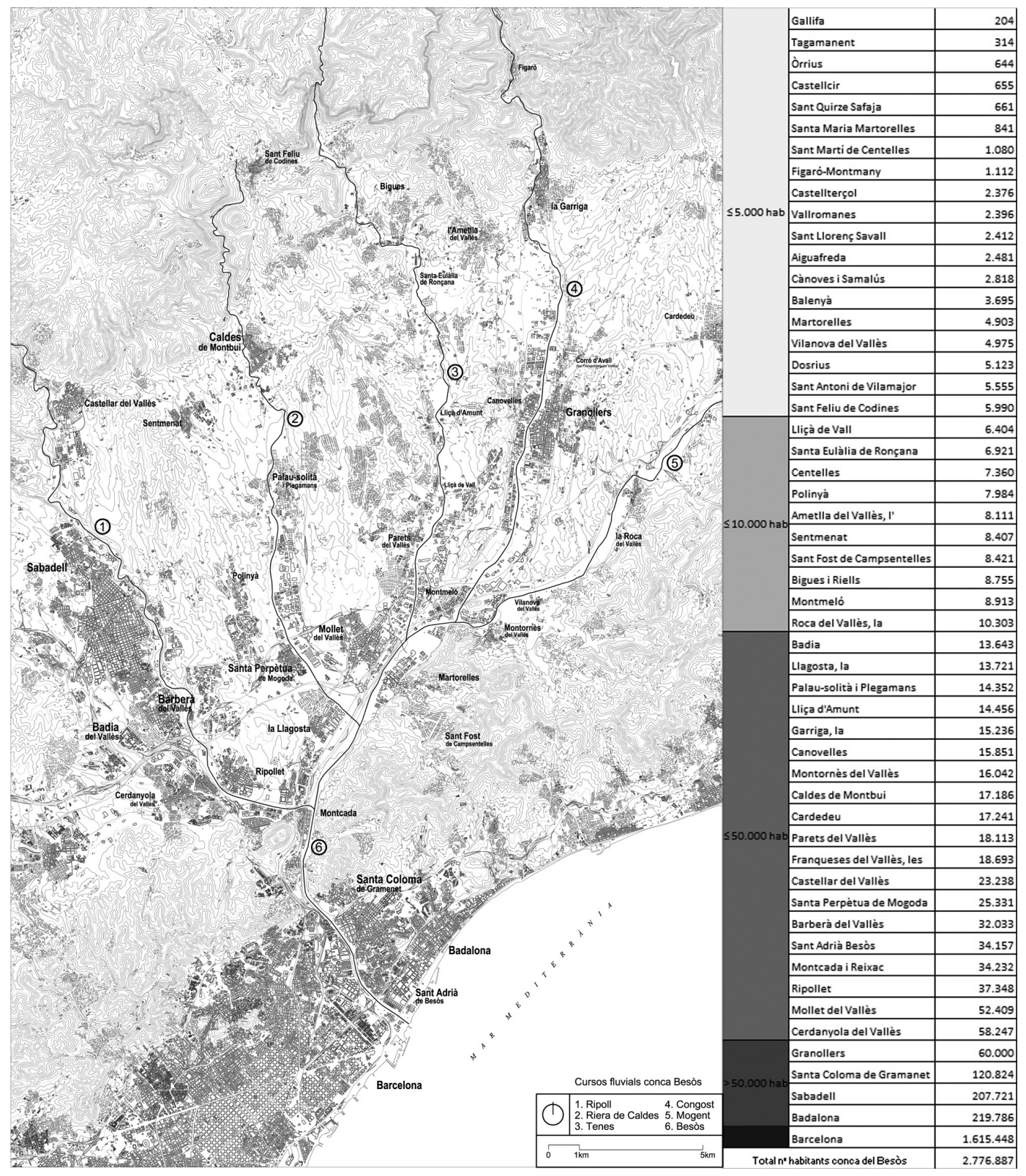

Figura 1. Assentaments urbans i cursos fluvials de la conca del Besòs.

Font: elaboració pròpia a partir de la base topogràfica de l'ICC i les dades de població d'IDESCAT (2011). 
nistracions públiques mesures urgents adequades per revertir la situació. És per això que les polítiques endegades pels primers governs democràtics de la Generalitat de Catalunya restablerta s'orienten principalment a millorar la qualitat de l'aigua, a assegurar-ne la disponibilitat i a prevenir el risc d'inundacions.

El primer pas important en aquest context d'urgència es fa amb la redacció del Pla de Sanejament de Catalunya (Generalitat de Catalunya, 1982), on s'estableixen els criteris generals d'intervenció, concretats més endavant a través del Pla Zonal de les Conques Llobregat-Besòs (Generalitat de Catalunya, 1985). Un cop fixades les bases tècniques i jurídiques corresponents, a partir de 1990, s'executen les diferents obres d'evacuació i tractament de les aigües residuals necessàries per conformar la xarxa de col-lectors i estacions depuradores de la regió metropolitana de Barcelona. Aquestes actuacions, juntament amb els plans de control dels abocaments de residus, comporten millores notables en la qualitat de les aigües de les dues conques metropolitanes ${ }^{1}$.

Durant aquesta primera fase, la gestió de l'aigua s'aborda des d'un enfocament sectorial i sense considerar l'ordenació de l'espai fluvial. La regulació normativa del sòl associat als rius i a les rieres s'efectua mitjançant un planejament urbanístic municipal sense visió de conjunt, indiferent a la capacitat vertebradora del sistema hídric i al seu potencial cívic i ecològic. Aquest enfocament fragmentari esdevé agreujat per l'heterogènia classificació del sòl associat al curs fluvial ${ }^{2}$. D'altra banda, el planejament d'aquest període no considera tampoc la naturalesa inundable de riberes i planes al.luvials que sovint s'integren al sòl urbà i van sent ocupades progressivament per enclavaments residencials i industrials.

\subsection{La Directiva Marc de l'Aigua. Vers una nova cultura de l'aigua}

A mesura que tenen efecte les actuacions de sanejament de les aigües residuals i la qualitat hídrica dels rius millora, s'assumeix progressivament la integració de les dimensions física i social de l'espai fluvial. Sota el marc normatiu del Pla Director dels Espais Fluvials de la Conca del Riu Besòs (Consorci per a la Defensa de la Conca del Riu Besòs, 2000), es redacten projectes de recuperació ambiental i d'arranjament de camins fluvials per a cadascuna de les subconques, alhora que s'inicien línies pròpies d'educació ambiental i de custòdia fluvial. Aquestes iniciatives exemplifiquen el canvi de paradigma en la gestió de l'aigua que consolida, de forma definitiva, la Directiva Marc de l'Aigua europea (Consell d'Europa, 2000a). Aquest nou marc normatiu obliga l'Administració catalana a homologar les prioritats i els instruments d'intervenció sota criteris de desenvolupament sostenible que integrin les institucions i la ciutadania mitjançant processos de participació.

1. Per consultar l'estat actual a la conca del Besòs, vegeu l'apartat «Sistemes de sanejament» del web http://www.besos.cat/.

2. Per consultar el planejament dels quatre municipis que travessa la riera de Caldes, vegeu: Ajuntament de la Llagosta, 1987; Ajuntament de Santa Perpètua de Mogoda, 1997 i 2007; Ajuntament de Palau-solità i Plegamans, 1978 i 2004, i Ajuntament de Caldes de Montbui, 2009. 
A Catalunya, la Directiva Marc de l'Aigua queda incorporada al Reglament de Planificació Hidrològica de Catalunya (Generalitat de Catalunya, 2006b), del qual depèn el Pla de Gestió del Districte de Conca Fluvial de Catalunya (Generalitat de Catalunya, 2010a) i els documents successius de planificació d'espais fluvials, en procés de redacció per a cada conca catalana. El propi Pla de Gestió del Districte de Conca Fluvial de Catalunya, vigent fins al 2015, inclou mesures i propostes sorgides dels processos participatius desenvolupats des del 2006, amb la contribució de 2.214 persones en representació de 1.692 entitats (ACA, 2012; Brugué, 2009). Pel que respecta al cas concret de la conca del Besòs, de les més de 150 propostes debatudes, en destaquen les de participació i comunicació incorporades a la Guia tècnica per a actuacions en riberes (Godé, 2008) i, especialment, la previsió del Consell de Conca del Besòs com a espai de mediació per mantenir el procés de participació a mitjà i a llarg terminis.

D'altra banda, la redacció dels documents derivats de Planificació d'Espais Fluvials també es basa en les orientacions de la ja esmentada Directiva Marc de l'Aigua, tant pel que fa a la preservació del medi com a la sensibilització de la població, i també en les indicacions de la posterior Directiva d'Avaluació i Gestió de les Inundacions (Consell d'Europa, 2007), en relació amb la prevenció dels riscos associats a les fortes riuades característiques dels règims fluvials mediterranis. Igualment, el nou Reglament de la Llei d'Urbanisme (Generalitat de Catalunya, 2006a) introdueix, al seu article 6 «Directrius de preservació enfront dels riscos d'inundació", una nova concepció funcional dels espais fluvials per tal de regular-ne solidàriament els criteris urbanístics, hidràulics i ambientals.

En definitiva, es pot afirmar que els principis bàsics de la nova cultura de l'aigua, el reconeixement de la funció ecològica i social dels rius com a bé comú que cal preservar i la inclusió de la ciutadania mitjançant processos participatius han estat plenament incorporats en el marc normatiu català vigent. També és cert, però, que l'actual conjuntura econòmica i política planteja greus incerteses sobre la continuïtat d'un procés exemplar d'assimilació dels principis de la Directiva Marc de l'Aigua europea. El fort endeutament de l'Agència Catalana de l'Aigua ha esdevingut un argument decisiu per desmantellar les polítiques realitzades fins ara i per impulsar la privatització progressiva de la gestió hídrica, en un context polític on la participació ciutadana ha deixat de ser prioritària (Font i Galais, 2011).

\subsection{El Conveni Europeu del Paisatge. Vers una nova cultura del paisatge}

També en aquests primers anys del segle XXI, la nova cultura del paisatge esdevé un tema rellevant en les polítiques territorials catalanes (Busquets, 2005; Tarroja i Camagni, 2006; Cortina, 2010; Nogué, 2010). Seguint les directrius establertes pel Conveni Europeu del Paisatge (Consell d'Europa, 2000b), la Generalitat de Catalunya aprova la Llei 8/2005, de protecció, gestió i ordenació del paisatge a Catalunya, i crea l'Observatori del Paisatge de Catalunya, des d'on s'endega la redacció dels catàlegs del paisatge, amb el propòsit d'incorporar els objectius paisatgístics en el planejament territorial. Aquest nou marc normatiu 
consolida una visió integrada que reconeix la multiplicitat de valors naturals i culturals del paisatge, a més de defensar la participació pública com a eina per implicar-hi i coresponsabilitzar-hi els ciutadans en la gestió i planificació. Per al cas concret dels corredors fluvials metropolitans, el Catàleg del paisatge de la regió metropolitana de Barcelona dóna suport a la continuïtat i a la qualitat dels entorns fluvials mitjançant l'assignació d'usos socials i naturals compatibles, a més de posar l'accent en la importància de la valoració social dels rius com a «referents per a la creació i recreació de la identitat del lloc» ${ }^{3}$. En sintonia amb aquests principis, es redacten les cartes del paisatge, com a instrument derivat d'aplicació local, supramunicipal o comarcal. Aquest és el cas de la Carta del paisatge de la vall del Tenes (Mancomunitat de la Vall del Tenes, 2009), dins la conca del Besòs, on s'identifica l'espai fluvial com a element físic de cohesió territorial i s'assenten les bases per assolir la concertació d'estratègies entre els diferents agents locals, públics i privats, encaminades al manteniment i la millora de la qualitat paisatgística de la vall del Tenes.

\subsection{Estratègies principals de revaloració dels paisatges fluvials metropolitans}

L'assumpció progressiva de les noves cultures de l'aigua i del paisatge, introduïdes en els apartats anteriors, comporta la implementació de processos de revaloració dels paisatges fluvials metropolitans, concebuts simultàniament com a corredors ecològics, espais patrimonials i aglutinadors socials. En aquest context, les tasques d'estricta reparació física s'enriqueixen amb propostes d'abast més ampli que integren la millora del medi natural amb l'apropament dels ciutadans als rius i a les rieres, autèntics detonants d'una identitat territorial pròpia. Pel que fa a la conca del Besòs, aquesta nova generació d'iniciatives adreçades al suport paral.lel dels valors ecològics i socials dels espais fluvials conté quatre línies de treball principals que es presenten a continuació: l'educació ambiental, el voluntariat ambiental, la pedagogia del patrimoni històric i la promoció del lleure. Es tracta d'estratègies habituals en els processos contemporanis de regeneració d'espais fluvials metropolitans, com il.lustra també el cas modèlic de l'Emscher Park (Government of North-Rhine Westphalia, 1989).

\section{L'educació ambiental}

Des de l'inici de la recuperació de la conca del Besòs, l'Administració pública ha desenvolupat una tasca pedagògica i de difusió important adreçada al ciutadà metropolità. Ho ha fet a través d'exposicions i publicacions com ara Viu el riu: Idees, propostes i paisatges per a la conca del riu Besòs (AADD, 1994), Ciutat i riu dins l'àmbit metropolità: La conca del Besòs (AADD, 1999) i El paisatge fluvial a la conca del Besòs: Ahir, avui..., i demà? (Gordi, 2005). Amb els anys, aquests treballs de difusió dels valors ambientals del conjunt de la conca han

3. El Catàleg del paisatge de la regió metropolitana de Barcelona està pendent d'aprovació inicial per part del Departament de Territori i Sostenibilitat. Les dades que aquí apareixen s'han extret d'un esborrany cedit per l'Observatori del Paisatge de Catalunya. 
adquirit un caràcter més tècnic i retrospectiu, d'avaluació de la feina feta, amb la celebració de trobades tècniques com ara les Jornades de Restauració d'Espais Fluvials de la Conca del Besòs (2009).

Paral-lelament, l'educació ambiental ha irromput amb força en el món docent, ja sigui a través d'activitats organitzades des dels propis centres per estudiar la millora del medi aquàtic, o des d'entitats externes que han proposat activitats pedagògiques per a escoles i instituts, com ara el programa Apropa't al Besòs, del Consorci per a la Defensa de la Conca del Riu Besòs o la línia d'educació ambiental del càmping El Pasqualet, a Caldes de Montbui (figura 2).

Progressivament, durant la dècada de 1990, la ciutadania, organitzada en forma d'entitats civils, impulsa, a una escala més local i sovint amb el patrocini de l'Administració municipal, nombroses iniciatives d'educació ambiental orientades al públic adult i al familiar a través de conferències i passejades de descoberta de la natura. Entitats locals força actives, com ara l'Associació per a la Defensa i l'Estudi de la Natura (Sabadell, 1982), l'associació Amics del Sender (Caldes de Montbui, 1997), l'associació Amics del Ripoll (Sabadell, 2000), l'associació de difusió i conservació del patrimoni natural LESTES (Santa Perpètua de Mogoda, 2001) i el Grup d’Ornitologia del Tenes (Santa Eulàlia de Ronçana, 2007) il.lustren el compromís de la societat civil a l'entorn de la conca del Besòs.

Totes aquestes iniciatives d'educació i promoció ambiental comparteixen un mateix objectiu de fons: donar a conèixer la dimensió natural que cal recu-

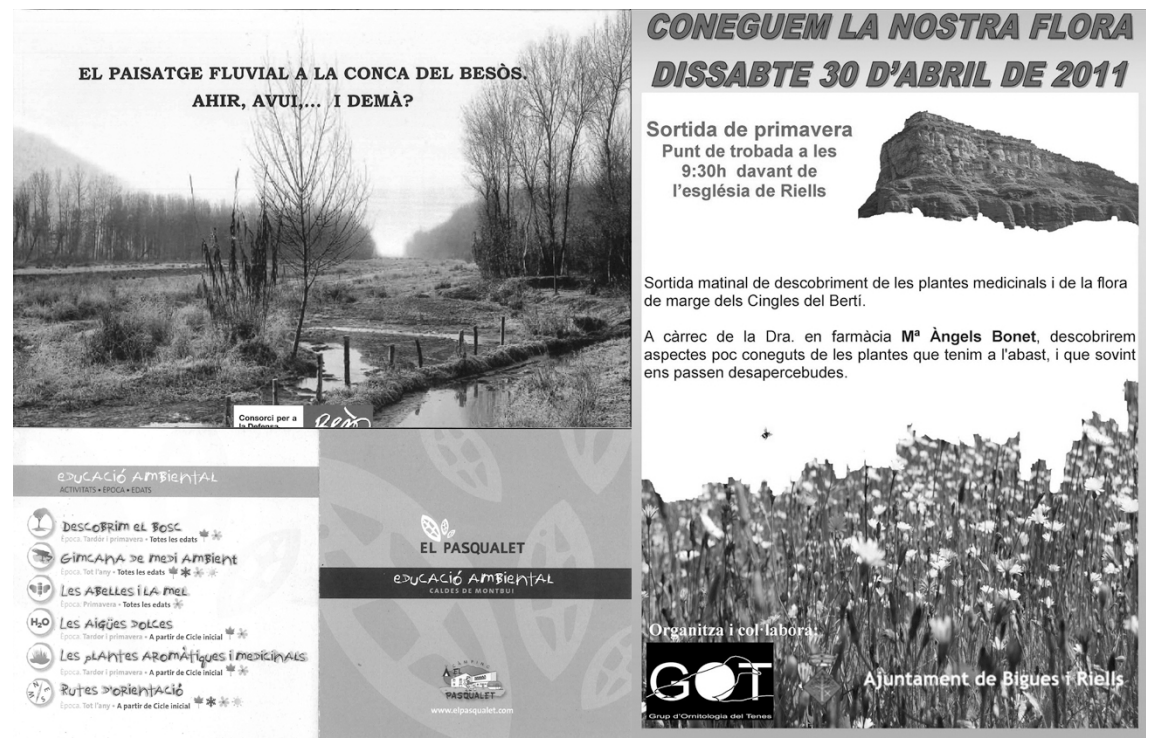

Figura 2. Iniciatives d'educació ambiental.

Font: Consorci per a la Defensa de la Conca del Riu Besòs (Granollers, 2005); Càmping El Pasqualet (Caldes de Montbui, 2012); Grup d'Ornitologia del Tenes (Bigues i Riells, 2011). 
perar de l'entorn fluvial, per tal de respectar-lo i preservar-lo com a bé comú. Per aconseguir aquest propòsit, és necessari, com en tot procés d'interpretació ambiental, desvetllar la curiositat, motivar i remarcar la importància d'allò que sembla petit però esdevé important (Tilden, 1957). En aquest sentit, el públic jove té un rol estratègic, per la seva receptivitat i capacitat d'aprendre valors nous, a més de les facilitats de disseminació que suposa introduir aquests programes dins de l'entorn educatiu. En canvi, fer arribar aquests coneixements a la resta de la població adulta és encara un repte per assolir i l'abast de les sortides de descoberta de la natura adreçades al públic familiar és minoritari.

\section{El voluntariat ambiental}

Un altre format molt efectiu de sensibilització, mitjançant la implicació directa dels ciutadans en la millora de l'entorn fluvial, ha estat el voluntariat. Un cop assolida una certa conscienciació ambiental gràcies als esforços realitzats durant la dècada de 1990, comencen a consolidar-se programes de voluntariat ambiental adreçats a recuperar els cursos fluvials. A Catalunya, el Projecte Rius, impulsat des de l'any 1997 per l'Associació Hàbitats, en col-laboració amb el Departament d'Ecologia de la Universitat de Barcelona i el Grup de Defensa del Ter, esdevé una iniciativa innovadora de sensibilització social que promou l'execució de tres tipus d'actuacions: inspeccions de l'estat ecològic dels rius, accions reivindicatives de neteja de les lleres i adopcions de trams fluvials ${ }^{4}$. Aquest programa, d'escala regional, s'executa a través de xarxes de voluntariat local encarregades de dur a terme actuacions en totes les conques, amb el suport tècnic i l'assessorament de l'entitat promotora de l'activitat. L'acollida d'aquest programa ha estat molt positiva i, segons l'Informe RiusCat 2011 (Associació Hàbitats, 2012), la conca del Besòs ha esdevingut la més participativa del territori català.

Juntament amb aquesta iniciativa regional i a una escala més local, les entitats civils, amb la colllaboració de les administracions municipals, han endegat programes de voluntariat amb ciutadans, escoles i empreses privades per organitzar plantades d'arbres, restauració de lleres i jornades de neteja de l'entorn fluvial. És el cas del projecte Fes reviure el Ripoll!, de l'ADENC, que promou la participació ciutadana mitjançant un exercici d'educació ambiental in situ en un tram del riu Ripoll a Sabadell, com també de les plantades d'arbres amb la participació d'alumnes dins la programació estable de les escoles de Santa Perpètua de Mogoda (celebració de la Festa de l'Arbre) o Palau-solità i Plegamans (projecte transversal de curs Arrelats a la terra, de l'escola La Marinada) (figura 3).

4. L'adopció de trams fluvials requereix un grau superior de compromís en relació amb la resta d'actuacions de sensibilització. El procés s'inicia formalment amb la signatura d'un acord de custòdia entre els diferents agents públics i privats implicats. Es redacta un projecte d'adopció que inclou informació bàsica sobre el procediment (Manual per a l'adopció de rius) i diverses propostes participatives de gestió ambiental i social adreçades a la millora del riu i el seu entorn. Actualment, s'estan duent a terme deu projectes d'adopció de trams fluvials a Catalunya. Per a més informació, vegeu: http://www.projecterius.org/adopcio. 


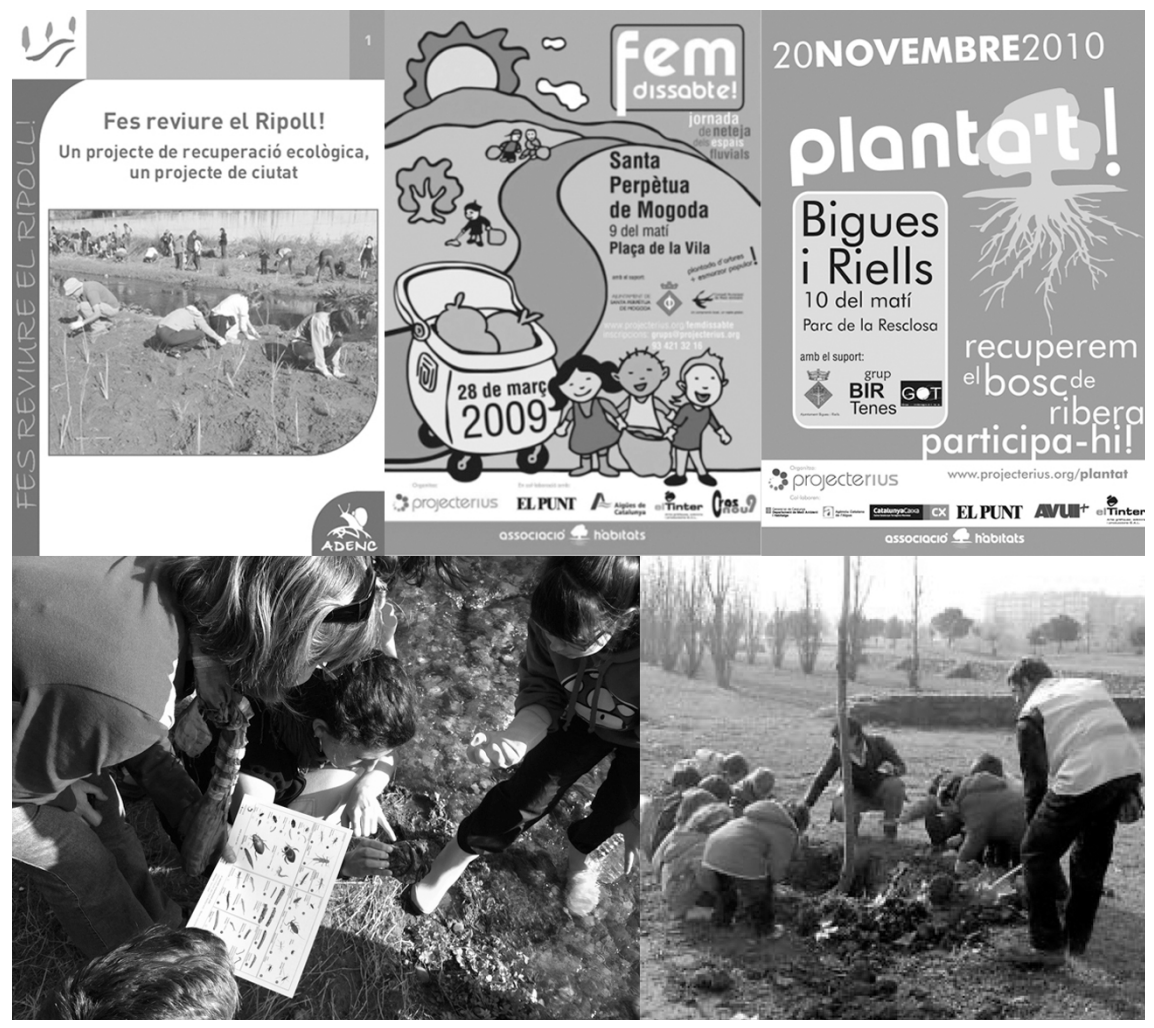

Figura 3. Iniciatives de voluntariat ambiental.

Font: ADENC (Sabadell, 2011); Associació Hàbitats (Santa Perpètua de Mogoda, 2009); Associació Hàbitats (Bigues i Riells, 2010). Fotografies: Marta Benages (Santa Perpètua de Mogoda, 2012) i L'Informatiu (Santa Perpètua de Mogoda, 2006).

S'ha demostrat que aquests programes són molt efectius per incrementar el sentiment de comunitat, l'autoestima, el compromís i la identificació amb l'entorn natural (Kaplan et al., 1998). En aquest sentit, el voluntariat ambiental conté un alt potencial cívic que permet, a través de l'acció desenvolupada sobre l'entorn, activar processos efectius d'apropiació ciutadana (Vidal i Pol, 2005). Amb aquest enfocament, durant els darrers trenta anys, ha proliferat el nombre d'entitats civils i d'iniciatives encaminades a promoure el voluntariat ambiental com a procés doble d'aprenentatge i servei a la comunitat a través d'activitats puntuals. Malgrat que, sovint, aquests esforços no han obtingut el grau de suport i consolidació necessari, en conjunt, han permès assolir la maduresa col-lectiva suficient per reivindicar, en el moment actual, la conveniència d'enfortir les xarxes de voluntariat mitjançant propostes a llarg termini i estructures organitzatives més sòlides i coordinades a nivell de conca. 


\section{La pedagogia del patrimoni històric}

En els darrers anys, la recuperació del patrimoni històric vinculat a l'aigua ha esdevingut una oportunitat per apropar la població als rius i a les rieres metropolitans. En termes generals, el patrimoni industrial i agrari del Besòs ha estat molt malmès per la sobrepressió urbana de les darreres dècades, però roman encara, especialment en les subconques, certa varietat d'elements patrimonials, com ara recs, mines d'aigua, molins i pous de glaç (Dantí, 2010). La recuperació i divulgació d'aquests materials permet elaborar una interpretació cultural del riu, complementària a la visió naturalista. Aquesta aproximació històrica aporta al ciutadà un coneixement valuós sobre el significat i la importància de l'entorn fluvial per als seus avantpassats, a més d'afavorir el naixement de vincles nous amb el riu basats en el respecte $\mathrm{i}$ l'admiració pel llegat local.

Durant l'última dècada, s'han impulsat, a la conca del Besòs, actuacions de catalogació, restauració i protecció normativa del patrimoni cultural. També s'han dut a terme iniciatives de difusió dels principals testimonis de l'aprofitament del recurs hídric en etapes anteriors. És el cas dels fullets divulgatius L'aigua i el patrimoni històric a la conca del Besòs (Dantí, 2010) o les publicacions editades a l'entorn del Parc Fluvial del Ripoll (AADD, 2003; Carbonell i Prat, 2003). Però, malgrat la profusió de catàlegs i de memòries sobre el patrimoni dels diversos municipis, són encara minoritàries les propostes d'itineraris que articulin els múltiples recursos culturals i naturals a l'entorn d'explicacions integrades sobre el paisatge fluvial. Segurament, la iniciativa de referència on el discurs cultural a l'entorn del riu es troba més consolidat és el Parc Fluvial del Ripoll, a Sabadell, amb quatre itineraris dedicats al patrimoni fluvial (Fernández i Prat, 2004), a més d'un pla per recuperar el patrimoni preindustrial del Ripoll (Ajuntament de Sabadell, 2006). També trobem dos casos rellevants que s'ubiquen en municipis del curs alt dels rius, allunyats de l'àrea d'influència de Barcelona. A Caldes de Montbui, la rehabilitació actual del passeig de la Riera i la restauració paisatgística posterior de l'entorn fluvial pretén articular els diversos elements de patrimoni vinculats al cicle de l'aigua (termes romanes, safareigs, hortes, molí fariner, etc. ${ }^{5}$ ) (Ajuntament de Caldes de Montbui, 2007). En la mateixa línia, entre els municipis de la Garriga, Figaró-Montmany i Tagamanent, l'Itinerari del Congost recupera una part de l'antic camí ral i senyalitza les peces més importants del patrimoni natural i cultural. En tots aquests casos, s'hi reconeix el vincle dels materials històrics amb el riu o la riera que els acull i els dóna sentit, a més d'oferir una interpretació solidària del paisatge fluvial mitjançant itineraris de descoberta del patrimoni natural i cultural (figura 4).

5. Per a més informació sobre els elements patrimonials vinculats a l'aigua, consulteu el web del museu Thermalia, de Caldes de Montbui (http://www.thermalia.cat/). 


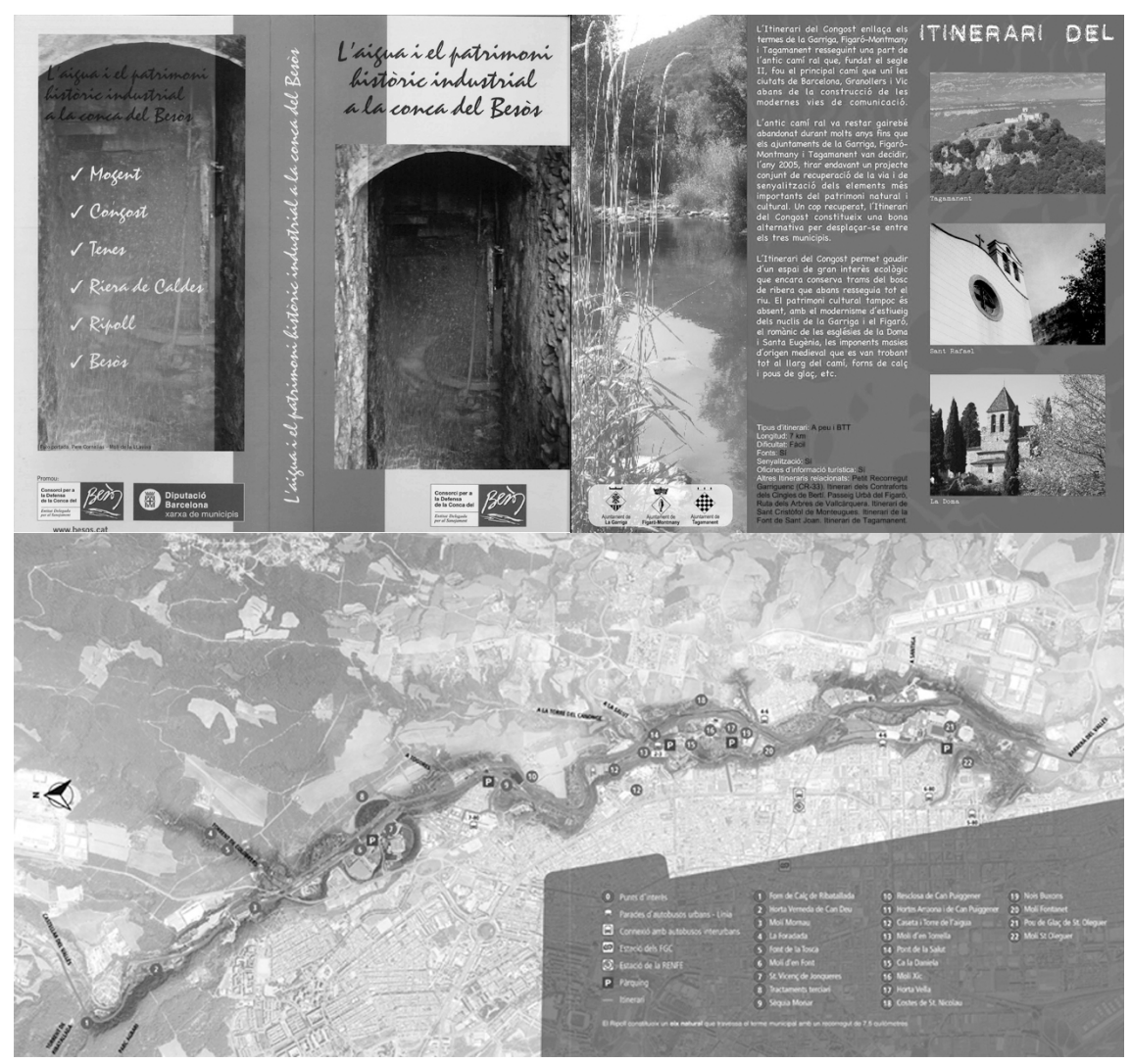

Figura 4. Iniciatives de pedagogia del patrimoni històric.

Font: Consorci per a la Defensa de la Conca del Riu Besòs (Granollers, 2010); Ajuntaments de la Garriga, Tagamanent i Figaró-Montmany, 2004-2009; Ajuntament de Sabadell, 2010.

\section{La promoció del lleure}

Les iniciatives descrites fins ara s'emmarquen en programes ambiciosos però d'incidència ciutadana limitada. Per tal d'accedir a un ventall més ampli de ciutadans i d'impulsar simultàniament la millora física de l'entorn fluvial i l'ús social respectuós, l'Administració ha apostat per la creació d'espais lúdics en trams concrets de forta afluència d'usuaris, compatible amb la protecció d'altres espais de ribera. En aquest context, el parc fluvial es consolida com a resposta a la demanda creixent d'indrets per al lleure ciutadà, i l'arranjament dels camins vora els rius i les rieres esdevé especialment necessari per articular els parcs fluvials amb els sistemes urbans propers. Els precedents d'aquesta estratègia a la conca del Besòs se situen a l'entorn del Ripoll, a la ciutat de Sabadell (Vidal, 1999), i al tram final del Besòs (Alarcón, 1999), segurament per la pressió urbana més gran exercida sobre el riu en aquests àmbits. Seguint l'exemple 
d'aquests casos pioners, cada cop són més nombrosos els municipis riberencs de la conca del Besòs que desenvolupen itineraris partint dels projectes constructius dels camins fluvials redactats durant l'any 2007 pel Consorci per a la Defensa de la Conca del Riu Besòs. Entre els més recents, trobem la Ronda Verda de Palau-solità i Plegamans (2011), el passeig de la Riera de Caldes de Montbui (2012) i el Camí Fluvial de Santa Eulàlia de Ronçana (2012). Aquests itineraris permeten articular els espais lliures urbans centrals amb un nou repertori de zones lliures periferiques de presència recurrent. Aquest és el cas dels parcs de ribera dels polígons industrials, com ara el Parc de l'Hostal del Fum, a Palausolità i Plegamans (23,4 ha); el Parc de Ribera, de Santa Perpètua de Mogoda (15,85 ha), i l'Espai Natural de Can Cabanyes, a Granollers (8 ha); de les zones d'hortes familiars municipals, com ara les de Gallecs, a Mollet del Vallès (4 ha), o les de la Plana del Molí, a Santa Perpètua de Mogoda (9,8 ha), i dels espais agraris i forestals protegits vora els cursos fluvials, com és el cas de la finca de Torre Marimon, a Caldes de Montbui (116,23 ha), i el Parc de l'Espai d'Interès Natural, de Gallecs (698,91 ha) (figura 5).

El conjunt d'aquestes iniciatives, adreçades a facilitar l'accés de la població a indrets riberencs d'estada $\mathrm{i}$ esbarjo, ha contribuït a ampliar el coneixement de l'espai fluvial i ha rebut una bona acollida ciutadana. Però, malgrat el valor i l'èxit dels projectes particulars, esdevenen preocupants les limitacions derivades d'un lideratge municipal excessivament fragmentat, com també la manca de la visió de conjunt i els esforços de coordinació necessaris que requereix la construcció d'un sistema coherent de parcs fluvials metropolitans.

L'anàlisi retrospectiva desenvolupada en els apartats precedents sobre les accions endegades durant els darrers trenta anys per revertir la degradació dels rius i afavorir l'apropiació ciutadana, permet calibrar la importància de l'esforç realitzat fins ara per l'Administració pública. S'han destinat copioses inversions per a la construcció i la gestió d'infraestructures de sanejament, la prevenció de riscos derivats d'episodis d'inundació, la recuperació ambiental d'espais fluvials, com també l'arranjament de camins i espais de lleure. Igualment, s'han esmerçat recursos a favor d'una pedagogia ciutadana d'emergència a l'entorn del medi fluvial, on l'educació i el voluntariat ambiental s'han combinat amb la promoció del lleure cultural i esportiu. Aquestes iniciatives han contribuït notablement a fer de l'espai fluvial un àmbit practicat per molts, i, poc a poc, ha augmentat el nombre d'individus compromesos amb la seva cura i valoració com a zona de gaudi quotidià farcit de valors estètics i afectius.

Certament, aquest esforç col-lectiu haurà de ser redimensionat d'acord amb les restriccions imposades pel context de crisi actual. Caldrà, segurament, dissenyar polítiques que permetin garantir el manteniment dels dispositius en funcionament $i$, alhora, reforçar el compromís ciutadà, especialment oportú per minorar la despesa pública en certes tasques de manteniment i millora ambiental, i progressar vers un model més madur de responsabilitat compartida. Per tant, paral-lelament a les tasques d'educació i millora de l'accessibilitat descrites, és convenient, per impulsar un discurs social responsable, identificar amb precisió les formes actuals d'apropiació de l'espai fluvial. Per aquest propòsit, esdevé 

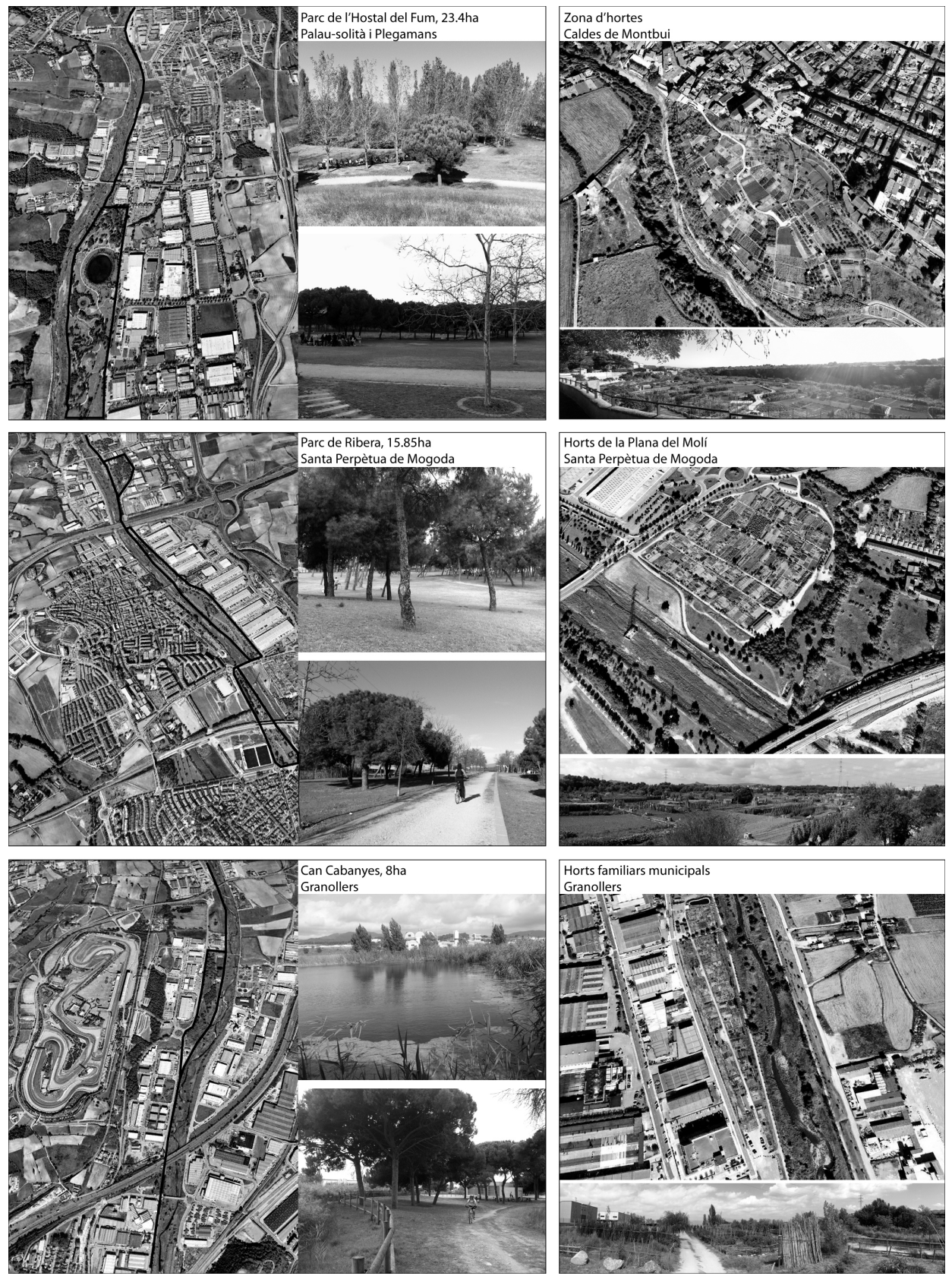

Figura 5. Parcs de ribera i horts urbans a l'entorn dels cursos fluvials de la conca del Besòs.

Font: imatges aèries de Google Earth. Fotografies: Marta Benages. 
imprescindible disposar d'eines especialitzades d'avaluació de la dimensió social del riu, que complementin el coneixement actual sobre la seva dimensió física. Amb aquest objectiu, l'apartat següent raona la conveniència d'incorporar la diagnosi geoetnogràfica com a instrument d'accés a la comprensió dels mecanismes d'utilització i apropiació dels corredors fluvials metropolitans.

\section{La diagnosi geoetnogràfica en la regeneració participada dels cursos fluvials metropolitans}

En termes generals, es pot afirmar que les iniciatives de suport a l'ús social dels cursos fluvials, presentades a l'apartat anterior, han estat induïdes «des de dalt» $\mathrm{i}$ basades principalment en un coneixement tècnic exhaustiu dels recursos naturals i culturals disponibles. Qüestions com ara la quantitat i la qualitat de l'aigua, la fauna i la flora, o els impactes ambientals ocasionats per la sobrepressió urbana, han estat els arguments recurrents de la pedagogia impulsada a l'entorn dels espais fluvials i adreçada a promoure una conducta ecològica responsable. Des del planejament urbanístic a la senyalització didàctica d'un itinerari, passant per les publicacions, les jornades divulgatives i les activitats diverses de sensibilització, s'ha descrit a bastament "com funciona» l'espai fluvial, però, en canvi, s'ha explorat molt poc sobre «com es viu» ${ }^{6}$. En definitiva, el vincle dels ciutadans amb el riu s'ha bastit primordialment de continguts tècnics mesurables, mentre que els continguts vivencials s'han relegat a un segon terme. Aquest desequilibri comporta un llast important per avançar vers la regeneració participada dels corredors fluvials metropolitans i posa en evidència la necessitat d'aprofundir en l'experiència vivencial com a punt de partida inexcusable. Més concretament, un coneixement millor del riu com a espai viscut comporta dos avantatges metodològics significatius estretament interrelacionats: ofereix una via d'accés a informació rellevant no visible sobre la vinculació dels ciutadans amb l'espai fluvial, i, alhora, facilita la comunicació entre ciutadans i tècnics en el decurs del procés regenerador.

En entorns especialitzats, l'experiència subjectiva és considerada una font de coneixement inestimable per comprendre els processos d'utilització, identificació i apropiació ciutadana de l'espai fluvial (Nogué, 2010; Molina et al., 2007; Reques, 2006). Els investigadors Siwan Lovett i Phil Price, de l'Australian River Restoration Centre, defensen que el coneixement "des de les persones» és del tot complementari amb l'enfocament tècnic del procés de restauració fluvial, i sostenen que cal donar-li més pes si es volen connectar els objectius mediambientals amb les prioritats socials en iniciatives de llarg recorregut ${ }^{7}$. Des d'aquest marc, els estudis de Buijs, Vallerani i Bigando, per citar-ne només

6. Existeixen pocs estudis que ens parlin del significat que tenen els rius de la regió metropolitana de Barcelona en l'activitat diària de les persones. Tot i així, convé destacar el projecte de Sitesize Riu Ripoll.net, un lloc web que planteja un exercici de representació de la identitat territorial de l'espai del riu Ripoll a la ciutat de Sabadell (consultable a: http://www.sitesize.net/riuripoll/).

7. Per a més informació, consulteu el web: http://australianriverrestorationcentre.com.au/. 
tres exemples internacionals rellevants, corroboren els efectes positius de la integració de la mirada tècnica d'intervenció sobre un indret i la mirada vivencial d'interacció amb aquest. Concretament, l'estudi recent de Buijs sobre els criteris de restauració fluvial a Holanda constata la relació directa entre el grau de satisfacció ciutadana i la llegibilitat dels nous espais fluvials, i reclama un procediment participat en les intervencions paisatgístiques que no només garanteixi l'acompliment d'objectius ecològics i de seguretat, sinó també la millora de la percepció que se'n té (Buijs, 2009). En la mateixa línia, Francesco Vallerani aposta per processos innovadors de restauració dels paisatges fluvials del Vèneto continental basats en la recuperació del sentit del lloc i l'arrelament, i defensa la importància de les "geografies mentals» en la construcció d'un imaginari positiu dels espais fluvials (Vallerani, 2012). Per últim, la metodologia d'investigació qualitativa desenvolupada per Bigando en àmbits periurbans francesos demostra l'existència d'una sensibilitat real dels habitants vers els seus paisatges quotidians, i remarca la necessitat de fer-la emergir per tal d'activar la mobilització ciutadana i afavorir els processos participatius (Bigando et al., 2011). Especialment, en el parc fluvial de la Gave du Pau, Bigando proposa un mètode de participació ciutadana que permet integrar les mirades dels tècnics i dels habitants (Bigando, 2010). L'aproximació a la dimensió vivencial de l'espai, efectuada a través d'entrevistes amb els residents en base a fotografies realitzades per ells mateixos, ha contribuitt a activar el treball mancomunat de diversos municipis a l'entorn d'un curs fluvial, conscienciar els quadres tècnics sobre els avantatges d'incorporar el coneixement dels habitants i consolidar un sentiment d'expertesa dels propis residents vers el seu paisatge quotidià (Bigando, 2010; Bigando et al., 2011). Pel que fa a l'àmbit local que ens ocupa, el Centre de Recerca Polis, de la Universitat de Barcelona, constitueix el referent principal en l'aplicació de mecanismes d'aproximació social al projecte regenerador de l'espai fluvial, assajats en diversos tallers participatius a l'entorn del tram baix del Besòs (Remesar i Pol, 2002; Remesar et al., 2004) ${ }^{8}$. Igualment, són cada vegada més nombrosos els geògrafs, els sociòlegs, els arquitectes i els urbanistes que, emparats pel mateix marc conceptual, promouen iniciatives de construcció col-lectiva de l'espai recollides en portals web com ara Vivero de iniciativas ciudadanas (AADD, 2011), o la wiki P2P Urbanism (P2P Foundation, 2011), o l'article de Cámara «Las iniciativas de participación ciudadana en el urbanismo» (2012: 20-21). Tot plegat posa de manifest l'interès que desperten aquestes pràctiques innovadores i la necessitat d'aprofundir en el que es configura com una línia de recerca emergent a l'entorn del coneixement vivencial de l'espai.

En aquest context, la diagnosi geoetnogràfica encaminada a descobrir l'espai viscut mereix una atenció especial. Tot seguit, se n'introdueixen els trets característics. Es tracta d'una metodologia de recerca qualitativa que integra aportacions del camp de la sociologia urbana (Mumford, 1991;

8. Centre de Recerca Polis, recull dels projectes de participació ciutadana desenvolupats i en procés de desenvolupament, consultables a: http://www.ub.edu/escult/index_participacio.html 
Lefebvre, 2000), la geografia humanista (Nogué, 1985), la psicologia ambiental (Valera, 1996) i l'urbanisme humanista (Jacobs, 2012; Cámara, 2012), amb l'objectiu d'abordar l'estudi de la dimensió vivencial de l'espai a partir de la interacció entre les pràctiques quotidianes, les representacions i el propi espai físic (Molina et al., 2007). La diagnosi geoetnogràfica es construeix a partir del diàleg constant entre la dimensió física de l'espai i els continguts antropològics, històrics i/o socials diversos que el caracteritzen (Matthews et al., 2005; Biffle i Thompson, 2006; Verd i Porcel, 2012). La diagnosi s'efectua en base a una recollida participada de dades i un tractament i una representació posteriors d'aquestes a través dels sistemes d'informació geogràfica $(\mathrm{SIG})$. La recollida de dades utilitza tres tècniques clàssiques properes a l'etnografia: la recerca documental, les entrevistes personals i l'observació participada (García Ballesteros, 1998). La combinació de totes tres permet recollir les visions múltiples, tant d'usuaris directes com de tècnics i altres informants més distants, i així captar la complexitat de la realitat socioespacial estudiada (Bertrand, 1974; Busquets, 1990). L'anàlisi i la representació posteriors de les dades qualitatives s'efectua mitjançant els nous SIG qualitatius, com a mecanismes capaços d'integrar i facilitar una comprensió més bona de materials d'origen i contingut molt divers. Aquests sistemes de representació socioespacial permeten:

1. Incorporar informació no geogràfica que aporta nous atributs espacials (Al-Kodmany, 2000; Verd i Porcel, 2012).

2. Representar significats vinculats a llocs determinats (Elwood, 2009).

3. Integrar enfocaments quantitatius i qualitatius per a l'anàlisi i la teorització inductiva de l'objecte d'estudi (Knigge i Cope, 2006; Matthews et al., 2005).

4. Oferir una plataforma comunitària per poder visualitzar, descriure i avaluar l'entorn (Rambaldi et al., 2004; Talen i Shah, 2007).

Com s'ha vist, a diferència de la diagnosi quantitativa i estratègica més pròpia dels processos de regeneració territorial induïts "des de dalt», la diagnosi qualitativa aposta pel valor del coneixement vivencial «des de baix» com a motor de processos ciutadans nous de representació i apropiació de l'espai fluvial. Per avançar en aquest camí, serà del tot necessari que hi hagi una cartografia renovada dels rius i de les rieres metropolitans, on el coneixement ciutadà permetrà identificar, juntament amb els valors naturals $\mathrm{i}$ culturals evidents, els valors vivencials latents del lloc; d'aquesta manera, el propi lloc i la seva condició d'espai viscut donaran sentit a les intervencions futures (Colafranceschi, 2012; Sala, 2012). Igualment, per aquest propòsit, serà també convenient assumir les limitacions derivades de l'encara escàs recorregut de la diagnosi geoetnogràfica i les presumibles dificultats per integrar-la en un marc metodològic d'ordenació i gestió urbanístiques, on el mecanisme de la zonificació estàndard preval sobre l'anàlisi de les especificitats vivencials (Colafranceschi, 2012). 


\section{Consideracions finals}

Després de trenta anys de polítiques adreçades a la recuperació dels rius catalans, els corredors fluvials de la conca del Besòs han esdevingut autèntics espais públics metropolitans, i són necessaris instruments que n'emfatitzin el valor col-lectiu i que incrementin la implicació de la població a tenir-ne cura. En aquest context, la diagnosi geoetnogràfica pot subministrar el coneixement vivencial necessari per alimentar els processos en curs de regeneració participada. Aquesta metodologia de recerca qualitativa esdevé especialment oportuna en el moment present, on convergeixen l'interès social creixent pels valors ambientals i paisatgístics dels espais fluvials metropolitans amb l'estalvi econòmic d'una gestió coresponsable.

En qualsevol cas, la conveniència d'incorporar el coneixement vivencial en el projecte territorial participat dels rius i les rieres s'ha d'entendre en continuiitat amb les polítiques desplegades fins ara a favor de la nova cultura del paisatge i de l'aigua. En aquest marc, la diagnosi geoetnogràfica adquireix sentit com a eina complementària, ben integrada als instruments vigents de planificació i dirigida a la construcció d'identitats territorials vigoroses. Amb aquest propòsit, disposar d'una cartografia de nova generació, orientada a reconèixer les múltiples varietats d'apropiació ciutadana a l'entorn dels corredors fluvials metropolitans, es perfila com un primer pas inexcusable.

\section{Referències bibliogràfiques}

AADD (1994). Àrea: Revista de debats territorials, 4. Diputació de Barcelona.

AADD (1999). "Ciutat i riu». Notes, 13. Centre d'Estudis Molletans.

AADD (2003). Arraona, 27, 4a època. Arxiu Històric de Sabadell i Museus de Sabadell.

AADD (2011). VIC. Vivero de Iniciativas Ciudadanas: Transferencias de la Innovación Ciudadana al Espacio Público [en línia]. <http://viveroiniciativasciudadanas.net/> [Consulta: 14 setembre 2012].

ACA (2012). Processos participatius i Directiva Marc de l'Aigua [en línia]. Barcelona: Generalitat de Catalunya. <http://aca-web.gencat.cat/aca/documents/ca/participacio/portal/index.pdf> [Consulta: 11 juliol 2012].

Ajuntament de Caldes de Montbui (2007). Projecte d'integració a l'espai públic urbà del torrent de Bugarai i riera de Caldes al seu pas per Caldes de Montbui.

- (2009). Pla d'Ordenació Urbanistica Municipal.

Ajuntament de la Llagosta (1987). Pla General d'Ordenació Urbana.

Ajuntament de Palau-solità i Plegamans (1978). Pla General d'Ordenació Urbana. Pla general d'ordenació de la comarca urbanistica de Sabadell.

- (2004). Modificació de Pla General d'Ordenació. Transcripció del Pla General de la Comarca de Sabadell al Terme Municipal de Palau-solità i Plegamans.

Ajuntament de Sabadell (2006). Pla per Recuperar el Patrimoni Preindustrial del Ripoll.

Ajuntament de Santa Perpètua de Mogoda (1997). Pla General d'Ordenació Urbana. 
- (2007). Modificació puntual del Pla General Municipal d'Ordenació de Santa Perpètua de Mogoda i adaptació al Pla Director Urbanistic de Santa Maria de Gallecs.

AlarCón, Antoni (1999). "La recuperació del riu Besòs a la desembocadura». Notes, $13,67-77$.

Al-Kodmany, Kheir (2000). «Extending geographic information systems (GIS) to meet neighborhood planning needs: Recent developements in the work of the University of Illinois at Chicago». The URISA Journal, 12 (3), 19-37.

Associacıó HàbITATS (ed.) (2012). Informe RiusCat 2011: L'estat de salut dels rius i rieres de Catalunya [en línia]. <http://projecterius.org/arxius/Informe_RiusCat_2011. pdf> [Consulta: 2 juliol 2012].

BARBA, Rosa (1994). «Els rius. Síntesis dels arguments de paisatge: A propòsit dels diversos tallers de projecte sobre els rius com a element paisatgístic». Àrea: Revista de Debats Territorials, 4, 72-91.

BATLLE, Enric (2011). El jardín de la metrópoli: Del paisaje romántico al espacio libre para una sociedad sostenible. Barcelona: Gustavo Gili.

BENAGES, Marta (2011). «Re-pensar la urbanidad en zonas residenciales de baja densidad desde la mirada comunitaria». A: VAll, Pere; MENDOZA, Carmen; CuÉllar, Álvaro; CARRACEDO, Óscar i BENAGES, Marta (eds.). LAU II. Regeneración de territorios intermedios. Repensar Encamp. Barcelona: Universitat Internacional de Catalunya, 82-87.

BERTRAND, M. (1974). «Espace et perception: discussion». L'Espace Géographique, 4, 238-240.

Biffle, Richard i Thompson, Pamela (2006). «Geo-ethnography, an interdisciplinary method for exploring schools, communities and cultures: Creating personal narratives of place and voice». The International Journal of Diversity in Organizations, Communities and Nations, 6 (3), 75-82.

Bigando, Eva (2010). Regards d'habitants sur les paysages du Gave de Pau au sein de l'agglomération paloise [en línia]. SET (UMR 5603) / CDAPP. <http://web.univpau.fr/ ftesson1/tesson/images/RAPPORT_SET_WEB.pdf> [Consulta: 20 juny 2012].

Bigando, Eva; Bercovitz, Rémi; Quintin, Alexia i Tesson, Frédéric (2011). «Paysages ordinaires et participations. La qualité médiatrice du paysage pour faire participer les habitants au processus décisionnel: une méthode originale mise en oeuvre dans l'agglomération paloise». Paysages de la vie quotidienne. Regards croisés entre recherche et action. Col.loqui internacional organitzat a Perpinyà i a Girona.

BRUguÉ, Quim (2009). "Deixem de jugar amb la participació ciutadana». Revista Òmnium [en línia], 13. <http://www.omnium.cat/ca/article/deixem-de-jugar-amb-la-participacio-ciutadana-3819.html> [Consulta: 17 desembre 2012].

BuIJS, Arjen (2009). "Public support for river restoration: A mixed-method study into local residents' support for and framing of river management and ecological restoration in the Dutch floodplains». Journal of Environmental Management, 90, 2680-2689.

BuSQUETS, Jaume (1990). «La percepció dels canvis espacials: El cas de Sant Cugat del Vallès». Documents d'Anàlisi Geogràfica, 16, 7-33.

- (2005). "Per una nova cultura del paisatge». Escola Catalana. Del paisatge $i$ les persones, 417, 6-9. Barcelona: Òmnium Cultural.

CÁMARA, Carlos (2012). «Las iniciativas de participación ciudadana en el urbanismo». URBS: Revista de Estudios Urbanos y Ciencias Sociales [en línia], 2 (1), 19-32. <http://nevada.ual.es:81/urbs/index.php/urbs/article/view/camara_menoyo> [Consulta: 28 juny 2012]. 
Cantó, Joaquín; Guardiola, Joaquín i Salvatella, Narciso (1975). «Evolución de la polución del agua del río Llobregat». Agua, 91, 15-24.

Carbonell, Óscar i Prat, Jordi (2003). Història gràfica del riu Ripoll al seu pas per Sabadell, 1864-1964. Sabadell: Ajuntament de Sabadell.

Colafranceschi, Daniela (2012). «Paisatge del conflicte, espai de diàleg». A: Nogué, Joan; Puigbert, Laura; Bretcha, Gemma i Losantos, Àgata (eds.). Franges: Els paisatges de la periferia. Olot: Observatori del Paisatge de Catalunya, 52-65.

Comisión Provincial de Urbanismo de Barcelona (1963). Plan Provincial de Barcelona. Col-legi d'Arquitectes de Catalunya, Arxiu Històric, Manuel Baldrich Tibau, H 110A / 7 / 102-113: Estructura urbanística i àrees de desenvolupament preferent.

Consell d'Europa (2000a). Directiva Marc de l'Aigua. 2000/60/CE de 23 d'octubre de 2000 .

- (2000b). Conveni Europeu del Paisatge [en línia]. <http://www.magrama.gob.es/ es/desarrollo-rural/temas/desarrollo-territorial/09047122800d2b59_tcm7-26223. pdf> [Consulta: 16 maig 2012].

- (2007). Directiva d'Avaluació i Gestió de les Inundacions. 2007/60/CE transposada a la legislació espanyola mitjançant el RD 903/2010, de 9 de juliol.

Consorci Per a la Defensa de la Conca del Riu Besós (2000). Pla Director dels Espais Fluvials de la Conca del Riu Besòs.

CORTINA, Albert (2010). Nova cultura del territori i ètica del paisatge. Barcelona: Generalitat de Catalunya. Documents de Recerca, 17.

DANTí, Jaume (coord.) (2010). L'Aigua i el patrimoni històric industrial a la conca del Besòs. Granollers: Consorci per a la Defensa de la Conca del Riu Besòs.

Díaz, Enrique i QueralT, Enric (1970). «Estudio de la polución de la cuenca del Pirineo Oriental». Documentos de Investigación Hidrológica, 9, 269-304.

ELWOOD, Sarah (2009). "Multiple representations, significations and epistemologies in community-based GIS». A: Cope, Megan i ElwOOD, Sarah (eds.). Qualitative GIS. A mixed methods approach. Londres: SAGE Publications Ltd.

FERNÁNDEZ, Charlotte (coord.) (2010). Cap a una estratègia participativa en urbanisme: Reflexions sobre un urbanisme participatiu de qualitat. Barcelona: Fundació Catalunya Segle XXI.

FERnÁNDEZ, Lluís i PRAT, Cesc (coords.) (2004). Quatre itineraris pel Ripoll a Sabadell: Guia del patrimoni fluvial. Sabadell: Amics del Ripoll.

FONT, Antonio (ed.) (2004). L'explosió de la ciutat: Transformacions territorials recents en les regions urbanes de l'Europa Meridional. Barcelona: Col.legi d'Arquitectes de Catalunya / Fòrum Universal de les Cultures de Barcelona.

FonT, Antonio; Llop, Carles i VILANOVA, Josep M. (1999). La construcció del territori metropolità: Morfogènesi de la regió urbana de Barcelona. Barcelona: Mancomunitat de Municipis de l’Àrea Metropolitana de Barcelona.

FOnT, Joan i Galais, Carolina (2011). "The Qualities of Local Participation: The Explanatory Role of Ideology, External Support and Civic Society as Organizer». International Journal of Urban and Regional Reserarch, 35 (5), 932-948.

FORMAN, Richard T. T. (2004). Mosaico territorial para la región metropolitana de Barcelona. Barcelona: Gustavo Gili.

GARCÍA, Evelyn i GODÉ, Lluís (2006). «La recuperación del Baix Llobregat. Evolución histórica». Congreso Nacional del Medio Ambiente, 8, Desarrollo rural y conservación de la naturaleza, Agua. Vitòria-Gasteiz.

García Ballesteros, Aurora (coord.) (1998). Métodos y técnicas cualitativas en geografía social. Barcelona: Oikos-Tau. 
Generalitat de Catalunya (1982). Pla de Sanejament de Catalunya.

- (1985). Pla Zonal de les Conques Llobregat-Besòs.

- (1987). Actuacions Industrials de l'Institut Català del Sòl. 1987.

- (1988). Actuacions Industrials de l'Institut Català del Sòl. 1988.

- (2006a). Reglament de la Llei d'Urbanisme de Catalunya. Decret 305/2006.

- (2006b). Reglament de Planificació Hidrològica de Catalunya. Decret 380/2006.

- (2010a). Pla de Gestió del Districte de Conca Fluvial de Catalunya. Decret 188/2010.

- (2010b). Pla Territorial Metropolità de Barcelona (PTMB). Generalitat de Catalunya, núm. 5627, 12 de maig.

GoDÉ, Lluís (dir.) (2008). La gestió i recuperació de la vegetació de ribera: Guia tècnica per a actuacions en riberes. Barcelona: Generalitat de Catalunya. Departament de Medi Ambient i Habitatge. Agència Catalana de l'Aigua.

Gord, Josep (dir.) (2005). El paisatge fluvial a la conca del Besòs. Ahir, avui..., i demà? Barcelona: Consorci per a la Defensa de la Conca del Riu Besòs.

Gordi, Josep (2008). «Els paisatges fluvials del Besós». Notes, 23, 105-128.

GOVERNMENT OF NORTH-RHINE WestPHALIA (1989). Internationale Bauausstellung Emscher Park: Workshop for the Future of Old Industrial Areas. Memorandum on Content and Organization. Gelsenkirchen: Gesellschaft Internationale Bauausstellung.

GutiérreZ, Aaron (2009). «El mètode Urban i la seva difusió com a valor afegit principal de la iniciativa comunitària». Documents d'Anàlisi Geogràfica, 53, 47-67.

JACOBS, Jane (2012). Muerte y vida de las grandes ciudades americanas. Madrid: Capitan Swing Libros, 1961.

Kaplan, Rachel; Kaplan, Stephen i Ryan, Robert L. (1998). With people in mind: Design and management of everyday nature. Washington, DC: Island Press.

KNIGGE, LaDona i Cope, Megan (2006). «Grounded visualization: Integrating the analysis of qualitative and quantitative data through grounded theory and visualization». Environment and Planning A, 38 (11), 20-37.

Lefebvre, Henri (2000). La production de l'espace. París: Anthropos, 1974.

LlOP, Carles (2008). «Paisatges metropolitans: policentrisme, dilatacions, multiperiferies i microperiferies: Del paisatge clixé al paisatge calidoscopi». Papers, 47, 9-13.

Luginbül, Yves (2008). «Paisatge i benestar individual i social». A: Nogué, Joan; Puigbert, Laura i Bretcha, Gemma (eds.). Paisatge i salut. Olot: Observatori del Paisatge de Catalunya; Barcelona: Generalitat de Catalunya, 16-35.

Mancomunitat de la Vall del Tenes (2009). Carta del paisatge de la vall del Tenes.

Margalef, Ramon i Prat, Narcís (1979). "La limnologia». Quaderns d'Ecologia Aplicada, 4, 9-23.

MatTHews, Stephen; DetMiler, James i BurTon, Linda (2005). «Geo-ethnography: Coupling Geographic Information Analysis Techniques with Ethnographic Methods in Urban Research». Cartographica The International Journal for Geographic Information and Geovisualization, 40 (4), 75-90.

Molina, Géraldine; Bertrand, Magali; Blod, Frédérique; Dascon, Juhane; Gambino, Mélanie i Milian, Johan (2007). «Géographie et représentations: De la nécessité des méthodes qualitatives». Recherches Qualitatives, Hors Série, 3. <http://geraldinemolina.org/recherche/publications-sous-page/> [Consulta: 28 març 2011].

Morris, Nina (2003). Health, well-being and open space. Literature review. Openspace Research Centre. Edinburgh College of Art. Heriot Watt University.

Mumford, Lewis (1991). "Whats is the city?». A: LeGATES, R. y StOut, F. (eds.). The city reader. Londres: Routledge, 1937. 
NEL·LO, Oriol (2006). «Els plans directors urbanístics: Una nova generació de plans». Espais, 52, 3-11.

Nilsson, Kjell i Nielsen, Anne Birgitte (2006). Urban Forestry for Human Health and Wellbeing. Copenhagen: Danish Center for Forest, Landscape \& Planning.

Nogué, Joan (1985). "Un mètode de treball humanista». Documents d'Anàlisi Geogràfica, 6, 67-80.

- (2010). Paisatge, territori i societat civil. València: Edicions Tres i Quatre.

Nogué, Joan; Puigbert, Laura i Bretcha, Gemma (eds.) (2008). Paisatge i salut. Olot: Observatori del Paisatge de Catalunya; Barcelona: Generalitat de Catalunya.

P2P Foundation (ed.) (2011). P2P Urbanism. P2P Foundation [en línia]. <http:// p2pfoundation.net/P2P_Urbanism> [Consulta: 14 setembre 2012].

PANAREDA, Josep M. (2009). «Evolución en la percepción del paisaje de ribera». Boletín de la $A G E, 51,305-324$.

PÉrez, Claudia i MARMolejo, Carlos (2008). «La localización intrametropolitana de las actividades de la innovación: Un anàlisis para la región metropolitana de Barcelona». Scipta Nova, XII, 270 (153).

Planas, Dolors; Vidal, Antoni i FolCh, Ramon (1976). «Problemàtica de les aigües continentals: Llibre blanc de la gestió de la natura als Països Catalans». Mem. Inst. Cat. Hist. Nat., 9. Barcelona: Barcino, 6-109.

Platt, Rutherford H. (ed.) (2006). The Humane Metropolis: People and Nature in the 21st-Century City. Cambridge: Lincoln Institute of Land Policy.

PRAT, Narcís (1979). «La xarxa hidrogràfica». Quaderns d'Ecologia Aplicada, 4, 87-107.

Prat, Narcís; Puig, M. Àngels i GonZÁlez, Glòria (1982-1983). Predicció i control de la qualitat de les aigües dels rius Besòs i Llobregat. Barcelona: Diputació de Barcelona. Servei de Medi Ambient.

PRAT, Narcís i Rieradevall, Maria (1992). «La degradació del riu Besòs». Lauro: Revista del Museu de Granollers, 15-19.

PuCHADES, Josep M. (1948). «El río Besós: estudio monográfico de hidrología fluvial». A: Miscelánea Almera. Barcelona: Diputació, 197-354.

Queralt, A. (1974). «La contaminación de las aguas». CAU, 25, 83-110.

Rambaldi, Giacomo; McCall, Mike; Weiner, Daniel; Mblie, Peter i Kyem, Peter (2004). Participatory GIS [en línia]. <http://www.iapad.org/participatory_gis.htm>.

REMESAR, Antoni i POL, Enric (2002). "Civic participation workshops in Sant Adrià de Besòs: a creative methodology». A: BenNeT, Sarah i BuTler, John (eds.). Locality, regeneration and divers[c]ities. Advances in Art \& Urban Futures 1. Bristol: Intellect, Ltd., 153-158.

Remesar, Antoni; Vidal, Tomeu; Valera, Sergi; Salas, Xavi; Ricart Ulldemolins, Núria; Hernández, A. i Remesar Aguilar, Nemo (2004). «Poblenou y La Mina [Barcelona], participación creativa con la metodología de las CPBoxes». On the Waterfront, 5, 53-74.

REQues, Pedro (2006). "La geografia de la percepción y del comportamiento: una introducción». V Jornadas Nacionales de Investigación en Psicologia. Santander.

RYDIN, Yvonne et al. (2012). «Shaping cities for health: Complexity and the planning of urban environaments in the 21 st century». The Lancet, 379, 2079-2108.

SALA, Pere (2012). «Periferies urbanes: L'experiència dels catàlegs de paisatge de Catalunya». A: Nogué, Joan; Puigbert, Laura; Bretcha, Gemma i Losantos, Agata (eds.). Franges: Els paisatges de la periferia. Olot: Observatori del Paisatge de Catalunya, 154-189.

SimON, Àngel (1994). «Per una política metropolitana d'espais lliures». Papers: regió metropolitana de Barcelona: Territori, estratègies, planejament, 20, 9-16. 
Talen, Emily i Shah, Swasti (2007). «Neighborhood Evaluation Using GIS: An Exploratory Study». Environment and Behavior, 39 (5), 583-615.

TARROJA, Alex i CAMAGNI, Roberto (coords.) (2006). Una nueva cultura del territorio: Criterios sociales y ambientales en las politicas y el gobierno del territorio. Barcelona: Diputació de Barcelona.

Tilden, Freeman (1957). Interpreting our Heritage. North Carolina: University of North Carolina Press.

Torra, Ramon; FARrero, Antoni i TÉNEZ, Víctor (2008). «La recuperació dels paisatges fluvials metropolitans: El projecte de recuperació ambiental i paisatgística del riu Llobregat a la comarca del Baix Llobregat». Papers, 47, 44-53.

TRULLÉN, Joan (2003). Economia de l'arc tecnològic de la regió metropolitana de Barcelona: Delimitació de pols i corredors, estructura econòmica $i$ indicadors d'economia del coneixement. Barcelona: Diputació de Barcelona. Serie Elements de Debat Territorial, 18.

VALERA, Sergi (1996). «Psicologia ambiental: bases teóricas y epistemológicas». Monografies psico-socio-ambientals, 9, 1-14.

VALL, Pere (2010). «Territorios intermedios en la región metropolitana de Barcelona. Identidad y reciclaje». Ciudad y territorio. Estudios territoriales, XIII (164), 267-283.

Vall, Pere; Koschinsky, Julia i MendozA, Carmen (2011). «Retrofitting suburbia through pre-urban patterns: introducing a European perspective». Urban Design International, 16, 171-187.

VALLERANI, Francesco (2012). «Franges hidràuliques, entre angoixes geogràfiques i estratègies de supervivència: El cas de la terra ferma de Venècia». A: NoGuÉ, Joan; Puigbert, Laura; Bretcha, Gemma i Losantos, Àgata (eds.). Franges: Els paisatges de la periferia. Olot: Observatori del Paisatge de Catalunya, 229-252.

VECSLIR, Lorena (2007). «Paisajes de la nueva centralidad». Urban, 12, 34-55.

VENDRELL, Jaume (1994). «Realitzacions i propostes metropolitanes en els espais públics: parcs, rius i platges». Papers, 20, 71-88.

Vendrell, Jaume i PRESMANES, Serafín (1993). «La recuperación de los ámbitos fluviales metropolitanos de Barcelona». OP. Revista del Colegio de Ingenieros de Caminos, Canales y Puertos [en línia], 26. <http://hispagua.cedex.es/sites/default/files/ hispagua_articulo/op/26/op26_5.htm> [Consulta: 18 abril 2012].

VERD, Joan Miquel i PORCEL, Sergio (2012). «An application of qualitative geographic information systems (GIS) in the field of urban sociology using ATLAS.ti: uses and reflections». Forum Qualitative Sozialforschung / Forum: Qualitavie Social Research [en línia], 13 (2), art. 14. <http://nbn-resolving.de/urn:nbn:de:0114-fqs1202144> [Consulta: 9 maig 2012].

VIDAL, Pere (1999). «El projecte del Parc Fluvial del Ripoll. Sabadell». Notes, 13, 91-116.

VIDAL, Tomeu i POL, Enric (2005). «La apropiación del espacio: Una propuesta teórica para comprender la vinculación entre las personas y los lugares». Anuario de Psicología, 36 (3), 281-297.

Zaitzevsky, Cynthia (1982). Frederick Law Olmsted and the Boston Park System. Cambridge: Harvard University Press. 